\title{
Mild Cognitive Impairment Subtypes and Type 2 Diabetes in Elderly Subjects
}

\author{
Silvia Valenza ${ }^{1,2}$, Lucia Paciaroni ${ }^{1}$, Susy Paolini ${ }^{1}$, Anna Rita Bonfigli ${ }^{3}{ }^{\circledR}$, Mirko Di Rosa ${ }^{4}($, \\ Rosa Anna Rabini ${ }^{5}$, Elena Tortato ${ }^{5}$, Paolo Pelliccioni ${ }^{6}$ iD and Giuseppe Pelliccioni ${ }^{1, * \mathbb{D}}$ \\ 1 Neurology Department, Italian National Research Center on Aging (IRCCS INRCA), 60100 Ancona, Italy; \\ silvia.valenza@ospedalimarchenord.it (S.V.); 1.paciaroni@inrca.it (L.P.); s.paolini@inrca.it (S.P.) \\ 2 Psychology Department, Azienda Ospedaliera Ospedali Riuniti Marche Nord, 61121 Pesaro-Fano, Italy \\ 3 Scientific Direction, Italian National Research Center on Aging (IRCCS INRCA), 60100 Ancona, Italy; \\ a.bonfigli@inrca.it \\ 4 Unit of Geriatric Pharmacoepidemiology and Biostatistics, Italian National Research Center on \\ Aging (IRCCS INRCA), 60124 Ancona, Italy; m.dirosa@inrca.it \\ 5 Metabolic Diseases and Diabetology Department, Italian National Research Center on Aging (IRCCS \\ INRCA), 60100 Ancona, Italy; rosaanna.rabini@sanita.marche.it (R.A.R.); e.tortato@inrca.it (E.T.) \\ 6 Eye Clinic, Polytechnic University of Marche, 60126 Ancona, Italy; paopel@hotmail.it \\ * Correspondence: g.pelliccioni@inrca.it
}

Received: 11 May 2020; Accepted: 24 June 2020; Published: 30 June 2020

\begin{abstract}
Background: Type 2 diabetes (T2D) is correlated to amnestic mild cognitive impairment (aMCI) and to non-amnestic mild cognitive impairment (naMCI). This study evaluated whether the T2D variable characterizes a peculiar cognitive profile in elderly patients. Moreover, it explores the association between glycated hemoglobin levels $(\mathrm{HbA1c})$, T2D duration, insulin and oral hypoglycemic agent treatment, and cognition in elderly diabetic patients. Methods: Detailed neuropsychological battery was used to diagnose MCI subtypes. A total of $39 \mathrm{MCI}$ subjects with T2D (T2D-MCI) and $37 \mathrm{MCI}$ subjects without T2D (ND-MCI), matched for age, educational level, and Mini-Mental State Examination score, were included. Results: ND-MCI performed worse in memory and language domains than T2D-MCI. The amnestic subtype is more frequent among ND-MCI and non-amnestic subtype in T2D-MCI. In T2D-MCI, high HbA1c levels correlate with episodic memory (immediate recall) and T2D duration. Some indexes of episodic memory (immediate recall), attention, and visual-spatial ability correlate with insulin treatment. Conclusions: An association between T2D and non-amnestic MCI is suggested. In the T2D-MCI group, significant associations between insulin treatment and memory (immediate recall), complex figure copy, and attention were found.
\end{abstract}

Keywords: cognitive functions; mild cognitive impairment; dementia; aging; type 2 diabetes; neuropsychological test; Alzheimer's disease

\section{Introduction}

Type 2 diabetes (T2D), a complex metabolic disease that may have significant effects on various organs of the body, has been found to be a risk factor for the development of dementia in multiple studies [1-3]. The mechanisms linking T2D with neurodegenerative disease, in particular with Alzheimer's disease (AD), remain unclear [4], but may include both cerebrovascular and neurodegenerative processes. Vascular risk factors associated with T2D, including hypertension, dyslipidemia, and obesity, have all been linked to a higher risk of dementia [5], while with regard to the neurodegenerative mechanisms, it has been observed that T2D can adversely affect the accumulation and processing of the amyloid beta protein [6,7]. Moreover, a long T2D duration may be associated with greater cerebral macrovascular disease, as well as clinical and subclinical cerebral infarctions that may impair cognitive function. 
Insulin has proved to be a crucial element for neurological functions. T2D and chronic peripheral hyperinsulinemia are associated with impairment in memory and cognitive functions. Furthermore, one important common mechanism between T2D and AD is impaired insulin signaling; moreover, a form of toxic amyloid can damage neuronal insulin receptors and affect insulin signaling and cell survival [8]. Recurrent or chronic hypoglycemia caused by insulin treatment may also contribute to permanent cognitive impairment [9].

Various studies have found an association in elderly patients between T2D and mild cognitive impairment (MCI) $[10,11]$, a condition manifesting in initial cognitive deficits that do not significantly interfere with the autonomy or social behavior of the patient [12]. MCI incidence is higher in individuals with T2D than in those without T2D [13]. T2D is considered a risk factor for MCI and this risk may be associated with the duration of T2D, use of glucose-lowering medications, and the degree of glucose control [14]. Moreover, Ma et al. showed that the presence of MCI in the T2D accelerated the median progression to dementia by 2.74 years [15].

Depending on whether memory is affected by the deterioration or not, $\mathrm{MCI}$ can be defined as amnestic MCI (aMCI) in which case the cognitive amnestic domain is primarily involved, and as non-amnestic MCI (naMCI) in which case the memory of the subject is not impaired.

However, research results on the association between T2D and the MCI subtypes are not entirely consistent, with some studies indicating greater memory impairment [16], others showing a cognitive profile characterized by a deficit in executive-attention and further functions without amnestic alteration [17].

This inconsistency in findings may largely be due to differences in the design of the studies or the criteria for the diagnosis of T2D and MCI.

Our study utilized an extensive neuropsychological battery to compare the cognitive performance of T2D-MCI and MCI subjects without diabetes (ND-MCI) and to determine whether the T2D variable characterizes a peculiar cognitive profile in elderly subjects. In addition, we aimed to explore the association between the levels of glycated hemoglobin ( $\mathrm{HbA1c}$ ), the duration of T2D, treatment with insulin, oral hypoglycemic agents, and cognition in T2D-MCI.

\section{Methods}

\subsection{Study Population and Recruitment}

The study was retrospective, observational, and cross-sectional with the recruitment site located at the INRCA Research Hospital in Ancona, Italy. A total of 39 T2D-MCI patients were compared with 37 ND-MCI matched patients. Both groups of patients visited the Neurology Department due to worries about their cognitive state.

Inclusion criteria allowed for subjects between the age of 70 and 85 with $\geq 5$ years of formal education, scoring $\geq 24$ on the global cognitive functioning test (Mini-Mental State Examination, MMSE) [18], demonstrating autonomy in everyday life, and having preserved or only slightly impaired functioning in complex daily activities. Autonomy in basic functions was investigated through the questionnaire Activities of Daily Living (ADL) [19], and that of complex functioning through Instrumental Activities of Daily Living (IADL) [20]. In addition to this, HbA1c, Body Mass Index (BMI), presence of hypertension, neuropathy, nephropathy, chronic renal failure, retinopathy, supra-aortic trunks arterial disease, obliterative arteriopathy of the lower limbs, and myocardial ischemia were clinically assessed according to the criteria of the Standards of Medical Care in Diabetes [21]. In particular, nephropathy was diagnosed on the basis of a urine albumin/creatinine ratio $>30 \mathrm{mg} / \mathrm{g}$, while chronic renal failure was present if the glomerular filtration rate was $<60 \mathrm{~mL} / \mathrm{min} / 1.73 \mathrm{~m}^{2}$.

The exclusion criteria consisted of psychiatric and neurological disorders (psychosis and major depressive disorders, cerebrovascular diseases, head injuries, cerebral tumors, Parkinson's disease, epilepsy, dementia). During the recruitment, the presence of T2D was assessed by clinical history and 
through laboratory assays, according to the diagnostic criteria established by the American Diabetes Association [21].

Patients with a new diagnosis of diabetes were treated according to clinical practice at the Diabetology Department of our institute.

The mean duration of diabetes was $17.5 \pm 11.9$ years. Seventeen subjects were treated with oral antidiabetic drugs, 14 with insulin of which 8 were treated with a combined therapy (insulin + oral antidiabetic agents), and only 8 subjects with diet therapy. In particular, among subjects treated with insulin, 10 subjects used rapid and long-acting insulin; one subject used rapid, long-acting, and pre-mixed insulin; one subject used only rapid-acting insulin; and 2 subjects used only long-acting insulin. Overall, the duration of insulin treatment was $8.6 \pm 6.4$ years.

The two groups (T2D-MCI and ND-MCI) were matched for age, educational level, and MMSE score. Information collected included data on vital signs, anthropometric factors, medical history, and behavior.

All participants gave their written informed consent for the enrollment in the present study. The study was approved by the INRCA IRCSS Ethics Committee of Ancona, Italy (Institutional Review Board), and the study protocol conformed to the principles of the Declaration of Helsinki.

The data sets supporting the results of this article are available in the Neurology Department INRCA IRCSS Ancona, Italy, repository.

\subsection{Diagnostic Criteria}

Diagnosis of MCI was made according to Petersen's criteria [12]: (1) subjective cognitive complaint, preferably confirmed by an informant; (2) objective impairment in performance on the cognitive test in the assessment battery, at least greater than 1.5 standard deviation below the scores of age- and education-matched normal aged individuals; (3) preserved global cognitive function; (4) essentially normal functional activities; (5) absence of dementia.

Mild cognitive impairment is subclassified into four subtypes by the presence of impairment in the memory domain (amnestic vs non-amnestic) and the number of impaired cognitive domains (single vs multiple): aMCI single-domain (aMCI-sd), aMCI multi-domain (aMCI-md), naMCI single-domain (naMCI-sd), naMCI multi-domain (naMCI-md) [22].

Given the number of subjects available, we considered it appropriate to classify patients on the basis of the presence or absence of the memory impairment, dividing them between aMCI and naMCI.

Each subject received a clinical evaluation and a standardized neuropsychological battery to verify the presence of the inclusion criteria. Neuropsychological assessment (Table 1) provided a large number of tests that allowed for the quantification of the subjects' performance in memory and other cognitive tests (language, visual-spatial skills, attention, and executive functions) and classification of the various subtypes.

To verify essentially normal functional activities, informant information was collected in all cases.

According to the pattern of impairment on the neuropsychological evaluation, all patients with MCI were classified as having aMCI if they had memory deficits in at least 2 memory tests. The patients were classified as having naMCI if they had at least 2 tests impaired in one non-memory domain [23]. In case of patients failing in at least 2 memory tests and having at least 2 tests impaired in one non-memory domain, they were classified only as aMCI. 
Table 1. Neuropsychological battery.

\begin{tabular}{|c|c|}
\hline \multirow{7}{*}{ Attention and executive functions } & Attention Matrices Test [24] \\
\hline & Trail Making Test A, TMT-A, and Trail Making Test, TMT-B [25] \\
\hline & Stroop Test [26] \\
\hline & Weigl's Sorting Test [27] \\
\hline & Multiple Features Target Cancellation Test (MFTC): time; accuracy; error [28] \\
\hline & Frontal Assessment Battery (FAB) [29] \\
\hline & Phonemic Fluency (FAS) [30] \\
\hline \multirow{5}{*}{ Memory } & Digit span [31] \\
\hline & Rey Auditory Verbal Learning Test: immediate and delayed recall [32] \\
\hline & Prose Memory Test [33] \\
\hline & $\begin{array}{l}\text { Free and Cued Selective Reminding Test (FCSRT): Immediate Free Recall (IFR); } \\
\text { Immediate Total Recall (ITR); Delayed Free Recall (DFR); Delayed Total Recall } \\
\text { (DTR); Index of Sensitivity Cueing (ISC) [34] }\end{array}$ \\
\hline & Rey-Osterrieth Complex Figure B: immediate and delayed recall [35] \\
\hline \multirow{5}{*}{ Language } & Animal fluency [36] \\
\hline & Fluency for semantic categories [37] \\
\hline & Oral comprehension [36] \\
\hline & Verbal Naming [36] \\
\hline & Noun Naming (CAGI) [37] \\
\hline Visual constructional ability & Rey-Osterrieth Complex Figure B copy [35] \\
\hline
\end{tabular}

\subsection{Statistical Analysis}

Firstly, the sample was analyzed for characteristics in terms of age, gender, years of education, cognitive state (identified by the MMSE score), HbA1c, Body Mass Index (BMI), presence of hypertension, neuropathy, nephropathy, chronic renal failure, retinopathy, supra-aortic trunks arterial disease, obliterative arteriopathy of the lower limbs, and myocardial ischemia comparing T2D-MCI and ND-MCI. For all continuous variables, the Shapiro-Wilk test for normality was calculated. Apart from gender, for which the proportions were analyzed, we also calculated mean and standard deviation for normally distributed variables, and the median and interquartile range for non-normally distributed variables. The same evaluation was carried out in terms of neuropsychological tests, reporting means and standard deviations (or medians and interquartile ranges) according to the two groups of subjects. To test if the differences between T2D-MCI and ND-MCI were statistically significant, parametric (Student- $t$ ) and non-parametric (Mann-Whitney $U$ ) tests were performed as appropriate. The association between T2D and neuropsychological tests was further investigated with stepwise linear regression analysis including the following confounders: gender, age, education, BMI, hypertension, neuropathy, nephropathy, chronic renal failure, retinopathy, supra-aortic trunks arterial disease, obliterative arteriopathy of the lower limbs, and myocardial ischemia. For normally distributed outcome variables, ordinary least squares linear regressions were estimated, while for non-normally distributed dependent variables, quantile (median) linear regressions were estimated. Thereafter, the chi-squared test was performed to evaluate the differences between MCI subtypes in T2D-MCI and ND-MCI subjects. Pearson's correlation coefficients for normally distributed variables and Spearman's rank correlation coefficients for non-normally distributed variables were calculated in order to evaluate the relationship among the neuropsychological tests and clinical features for T2D-MCI subjects.

All analyses were performed using SPSS 17.0 (SPSS Inc., Chicago, IL, USA) and the STATA version 15.1 Statistical Software Package for Windows (StataCorp, Collge Station, TX, USA); a value of 0.05 was considered significant. 


\section{Results}

The demographic variables and clinical characteristics of T2D-MCI and ND-MCI are shown in Table 2. All continuous variables are normally distributed with the exception of the MMSE $(p=0.59)$. There were no significant differences of gender, age, education level, and MMSE score between the two groups.

Table 2. Demographic data and clinical characteristics of mild cognitive impairment (MCI) with type 2 diabetes (T2D)-MCI and MCI subjects without diabetes (ND-MCI).

\begin{tabular}{|c|c|c|c|}
\hline & $\begin{array}{c}\text { T2D-MCI } \\
n=39\end{array}$ & $\begin{array}{c}\text { ND-MCI } \\
n=37\end{array}$ & $p$ \\
\hline Age $*$, mean $(\mathrm{sd})$ & $74.21(4.58)$ & $76.68(6.30)$ & 0.06 \\
\hline Female, $n(\%)$ & $18(46.15)$ & $22(59.46)$ & 0.25 \\
\hline Education (years) $*$, mean $(\mathrm{sd})$ & $7.44(2.98)$ & $8.27(3.90)$ & 0.30 \\
\hline $\mathrm{MMSE}^{\wedge}$, median (iqr) & $26.30(2.40)$ & $25.70(2.00)$ & 0.10 \\
\hline $\mathrm{HbA} 1 \mathrm{c} *$, mean $(\mathrm{sd})$ & $7.62(1.67)$ & $5.30(0.80)$ & 0.01 \\
\hline $\mathrm{BMI} *$, mean $(\mathrm{sd})$ & $28.33(5.23)$ & $23.63(2.50)$ & 0.00 \\
\hline Hypertension, $n(\%)$ & $26(66.67)$ & $18(48.65)$ & 0.11 \\
\hline Neuropathy, $n(\%)$ & $6(15.38)$ & $0(0.00)$ & 0.01 \\
\hline Nephropathy, $n(\%)$ & $3(7.69)$ & $0(0.00)$ & 0.09 \\
\hline Chronic Renal Failure, $n(\%)$ & $2(5.13)$ & $1(2.70)$ & 0.59 \\
\hline Retinopathy, $n(\%)$ & $13(33.33)$ & $0(0.00)$ & 0.00 \\
\hline Supra-aortic Trunks Arterial Disease, $n(\%)$ & $2(5.13)$ & $1(2.70)$ & 0.59 \\
\hline Obliterative Arteriopathy of Lower Limbs, $n(\%)$ & $5(12.82)$ & $2(5.41)$ & 0.26 \\
\hline Myocardial Ischemia, $n(\%)$ & $9(23.08)$ & $14(37.84)$ & 0.16 \\
\hline
\end{tabular}

$p$ from $t$-test for normally distributed variables $\left({ }^{*}\right)$, Mann-Whitney $\mathrm{U}$ test for non-normally distributed variables $\left({ }^{\wedge}\right)$, and $\chi^{2}$ for dichotomic variables.

Table 3 shows the significant differences between T2D-MCI and ND-MCI in neuropsychological tests. ND-MCI showed a significantly worse performance in some indexes of memory compared to T2D-MCI $(p \leq 0.05)$. Moreover, the comparison between the two groups revealed significant differences in the language tests: ND-MCI subjects obtained statistically significant lower scores in Noun Naming and Semantic Fluency tests (fluency for semantic categories and animal fluency) $(p \leq 0.05)$.

Table 3. Significative comparison of performance on neuropsychological tests between T2D-MCI and ND-MCI.

\begin{tabular}{cccccc}
\hline & \multicolumn{2}{c}{ T2D-MCI } & \multicolumn{2}{c}{ ND-MCI } & \multirow{2}{*}{$p$} \\
\cline { 2 - 5 } & Mean/Median & SD/IQR & Mean/Median & SD/IQR & \\
\hline FCSRT ITR (immediate total recall) $^{*}$ & 35.25 & 1.31 & 34.38 & 2.25 & 0.04 \\
\hline FCSRT DTR (Delayed Total Recall) $^{*}$ & 11.60 & 0.75 & 11.03 & 1.58 & 0.05 \\
\hline FCSRT ISC (Index of Sensitivity of Cueing) $^{*}$ & 0.95 & 0.06 & 0.91 & 0.11 & 0.03 \\
\hline Rey Auditory Verbal Learning Test (delayed recall) $^{\wedge}$ & 6.90 & 3.70 & 5.30 & 4.70 & 0.02 \\
\hline Prose Memory Test $^{\wedge}$ & 12.50 & 7.50 & 10.00 & 4.50 & 0.01 \\
\hline Rey-Osterrieth Complex Figure B (delayed recall) $^{\wedge}$ & 16.51 & 5.59 & 13.98 & 5.27 & 0.05 \\
\hline Fluency for semantic categories $^{\wedge}$ & 40.30 & 9.19 & 36.30 & 8.42 & 0.01 \\
\hline Animal fluency $^{\wedge}$ & 16.50 & 6.60 & 14.00 & 4.40 & 0.03 \\
\hline Noun Naming (CAGI) $^{*}$ & 45.04 & 2.03 & 44.00 & 1.95 & 0.02 \\
\hline
\end{tabular}

Normally distributed variables $\left(^{*}\right)$ are expressed as mean, standard deviation (SD) and $p$ from $t$-test; non-normally distributed variables ( $\left(^{\wedge}\right.$ ) are expressed as median, interquartile range (IQR), and $p$ from Mann-Whitney $\mathrm{U}$ test. 
These results are also confirmed after the introduction of possible confounders in the multivariate analysis (Table 4).

Table 4. Effect of T2D on each neuropsychological test in fully adjusted stepwise linear regression analysis: un-standardized betas (B) \pm standard error (SE) and level of significance $(p)$.

\begin{tabular}{ccc}
\hline Independent Variables: & B \pm SE & $p$ \\
\hline FCSRT ITR (immediate total recall) $^{*}$ & $1.09 \pm 0.41$ & 0.01 \\
\hline FCSRT DTR (Delayed Total Recall) $^{*}$ & $0.70 \pm 0.26$ & 0.01 \\
\hline FCSRT ISC (Index of Sensitivity of Cueing) $^{*}$ & $0.06 \pm 0.02$ & 0.01 \\
\hline Prose Memory Test $^{\wedge}$ & $3.00 \pm 0.63$ & 0.00 \\
\hline Rey-Osterrieth Complex Figure B (delayed recall) $^{\wedge}$ & $5.49 \pm 1.32$ & 0.00 \\
\hline Fluency for semantic categories $^{\wedge}$ & $3.99 \pm 1.32$ & 0.00 \\
\hline Animal fluency & & 0.01 \\
\hline Noun Naming (CAGI) & & 0.01 \\
\hline
\end{tabular}

Coefficients were estimated with ordinary least squares linear regression for normally distributed variables $\left(^{*}\right)$ and with quantile (median) linear regression for non-normally distributed variables (^). Each model is adjusted for gender, age, education, BMI, and clinical complications of diabetes (hypertension, neuropathy, nephropathy, chronic renal failure, retinopathy, supra-aortic trunks arterial disease, obliterative arteriopathy of the lower limbs, and myocardial ischemia).

Evaluating confounders, age, education, BMI, and clinical complications of diabetes showed a statistically significant association with the performance on neuropsychological tests.

Figure 1 shows the prevalence of MCI subtypes (amnestic or non-amnestic) according to the presence or absence of T2D. It emerges that in the T2D-MCI group, naMCI subjects are more frequent ( $59 \%$ naMCI vs $41 \%$ aMCI), while in the ND-MCI group aMCI are prevalent ( $30 \%$ naMCI vs $70 \%$ aMCI). This result was tested by means of the chi-square test and the differences are statistically significant $(p=0.010)$.

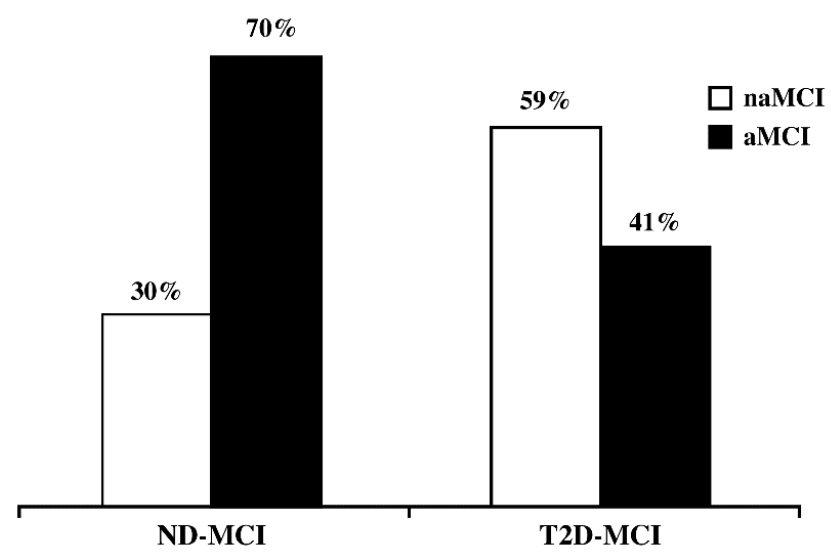

Figure 1. Prevalence of MCI subtypes in ND-MCI and T2D-MCI (\%). $p$ from $\chi^{2}$ test $=0.010$.

In a secondary analysis, we also examined the correlation between $\mathrm{HbA1c}$ levels, insulin treatment, oral hypoglycemic agents, T2D duration, and cognition in T2D-MCI (Table 5).

A significant inverse association was found between $\mathrm{HbA} 1 \mathrm{c}$ and episodic memory (immediate recall). In addition, further significant inverse correlations were found between the duration of T2D and visual spatial memory (immediate recall), complex figure reproduction, and Multiple Features Target Cancellation Test (MFTC) (accuracy index). Significant inverse associations between insulin treatment and memory (immediate recall), complex figure copy, and attention were also seen, as well as a significant direct association between insulin treatment and MFTC Test (time index). 
Table 5. Pearson's and Spearman's correlations (r) between cognition and clinical features in T2D-MCI.

\begin{tabular}{|c|c|c|c|}
\hline & HbA1c & Duration of T2D & Insulin Treatment \\
\hline $\begin{array}{l}\text { Rey Auditory Verbal Learning Test } \\
\text { (immediate recall)* }\end{array}$ & $\begin{array}{c}\mathrm{r}=-0.37 \\
p=0.03\end{array}$ & $\begin{array}{c}\mathrm{r}=-0.27 \\
p=0.11\end{array}$ & $\begin{array}{c}\mathrm{r}=-0.39 \\
p=0.02\end{array}$ \\
\hline $\begin{array}{c}\text { Rey Auditory Verbal Learning Test } \\
\text { (delayed recall)^ }\end{array}$ & $\begin{array}{c}\mathrm{r}=-0.13 \\
p=0.47\end{array}$ & $\begin{array}{c}\mathrm{r}=-0.02 \\
p=0.89\end{array}$ & $\begin{array}{c}\mathrm{r}=-0.33 \\
p=0.06\end{array}$ \\
\hline $\begin{array}{l}\text { Rey-Osterrieth Complex Figure B } \\
\text { (immediate recall) }\end{array}$ & $\begin{array}{c}\mathrm{r}=-0.30 \\
p=0.09\end{array}$ & $\begin{array}{c}\mathrm{r}=-0.38 \\
p=0.02\end{array}$ & $\begin{array}{c}\mathrm{r}=-0.25 \\
p=0.14\end{array}$ \\
\hline Rey-Osterrieth Complex Figure B (copy)^ & $\begin{array}{c}\mathrm{r}=-0.28 \\
p=0.11\end{array}$ & $\begin{array}{c}\mathrm{r}=-0.45 \\
p=0.01\end{array}$ & $\begin{array}{c}\mathrm{r}=-0.33 \\
p=0.05\end{array}$ \\
\hline Attention Matrices Test ${ }^{\wedge}$ & $\begin{array}{c}\mathrm{r}=-0.32 \\
p=0.58\end{array}$ & $\begin{array}{c}\mathrm{r}=-0.24 \\
p=0.16\end{array}$ & $\begin{array}{c}\mathrm{r}=-0.45 \\
p=0.01\end{array}$ \\
\hline MFTC Test (time index) ${ }^{*}$ & $\begin{array}{l}\mathrm{r}=0.21 \\
p=0.23\end{array}$ & $\begin{array}{l}\mathrm{r}=0.21 \\
p=0.22\end{array}$ & $\begin{array}{l}\mathrm{r}=0.37 \\
p=0.02\end{array}$ \\
\hline MFTC Test (accuracy index)* & $\begin{array}{c}\mathrm{r}=-0.18 \\
p=0.31\end{array}$ & $\begin{array}{c}r=-0.34 \\
p=0.03\end{array}$ & $\begin{array}{l}\mathrm{r}=0.09 \\
p=0.34\end{array}$ \\
\hline
\end{tabular}

$\mathrm{r}=$ Pearson's correlation coefficients for normally distributed variables ${ }^{*}$ ) or Spearman's correlation coefficients for non-normally distributed variables $\left({ }^{\wedge}\right)$.

A bivariate analysis between oral hypoglycemic agents and cognitive function did not reveal any significant results (Figure 2).


Figure 2. Box-and-whisker plot showing differences in cognitive function tests for T2D-MCI on insulin therapy and hypoglycemic agents. Data are presented as median (interquartile range). Statistical significance tested with Mann-Whitney $\mathrm{U}$ tests $\left({ }^{*} p<0.05 ;{ }^{* *} p<0.01\right)$. 


\section{Discussion}

Increasing evidence indicates a potential effect of T2D on the risk of cognitive dysfunction; however, the correlation between T2D and a cognitive impairment risk is still unclear [38].

Our study suggests that T2D is associated with an increased risk of a subtype of cognitive impairment. In fact, we found that among T2D-MCI the naMCI subtype prevails, while aMCI is most frequently found in ND-MCI.

Differences in the association of diabetes across MCI subtypes raise questions regarding the role of diabetes in the etiology and prognosis of MCI subtypes. Some studies in fact have found a relationship between diabetes mellitus type 2 and MCI [39,40], an intermediate stage between the expected cognitive decline of normal aging and the more serious decline of dementia.

In accordance with the results of a wide variety of highly reproducible studies, aMCI generally characterizes a subtype of patients who have a greater likelihood of progressing to AD [41], while naMCI seems to be related to non-AD forms [42].

In our patients, the T2D-MCI group showed less damage to memory functions compared to those without T2D (ND-MCI). These data were also corroborated by the significantly worse scores of the ND-MCI group in two indices of the memory test Free and Cued Selective Reminding Test (FCSRT) (Immediate Total Recall (ITR) and Index of Sensitivity Cueing (ISC)).

FCSRT can be used to assess specific features of episodic memory impairment as it controls for encoding at the time of study and provides retrieval cues at the time of memory testing. Furthermore, ITR and ISC indices, which control for the encoding and the magnitude of sensitivity to semantic cues, are proposed as specific markers of a deficit in hippocampal memory [43].

In T2D-MCI, the memory deficit is primarily related to a reduced attention capacity and inefficient strategies for information recovery, resulting from the dysfunctional executive systems and, therefore, non-amnestic in nature.

On the other hand, in ND-MCI, the memory deficit is both deeper and connected to problems of storage and authentic encoding, therefore, amnestic in nature.

Our results are confirmed also after the introduction in the multivariate analysis of other factors associated with T2D/ND and MCI (gender, age, education, BMI, hypertension, neuropathy, nephropathy, chronic renal failure, retinopathy, supra-aortic trunks arterial disease, obliterative arteriopathy of the lower limbs, and myocardial ischemia).

In addition, ND-MCI shows greater difficulties in the lexical access, with a semantic memory damage compatible with the AD pattern [44]. This agrees with some studies that have not only shown a different pattern between T2D-MCI and ND-MCI, but also a different trend over time: while T2D-MCI usually remains stable, ND-MCI tends to get worse especially in the amnesic components $[45,46]$. However, different neuropathological studies showed inconclusive results, not finding an increased frequency of any particular type of dementia in diabetic patients submitted to autopsy [47].

The correlations between clinical variables and cognitive tests provided further confirmation of these data. In our study, the relationship between the level of glycated hemoglobin and the cognitive tests was also assessed. The resulting data show that an increase of glycated hemoglobin is associated with a significant reduction in the scores on a test on verbal memory for immediate recall, and that the duration of T2D is associated with worse attention functions and visual-spatial ability. We furthermore found that the use of insulin inversely correlated to memory and visual-spatial tests, highlighting that patients with insulin therapy are prone to neuronal damage and cognitive impairment [48]. Other prospective studies evaluated the effects of antidiabetic therapy on conversion from T2D-MCI to dementia. Ma et al. found that dementia risk was significantly decreased among patients using oral hypoglycemic agents compared to insulin-treated patients [15]. These findings are confirmed by different studies, which have found that T2D increases the risk of dementia, principally in patients treated with insulin $[2,5,49]$.

The nature of this association seems to be insulin resistance (leading cause of T2D) in brain cells, with an impairment in their activities, thereby determining the onset of typical symptoms of AD $[49,50]$. 
In addition, animal studies have demonstrated that neurons can generate insulin, and insulin receptors have been found in key areas of the brain involved with AD pathology and cognitive function [51,52]. Due to the role of insulin in glucose regulation, insulin abnormalities may likely impair cerebral glucose metabolism, a characteristic which has been demonstrated in both AD and MCI brains [53,54].

The molecular mechanisms underlying this crosstalk are still elusive, as well as how central and peripheral insulin signaling operate in AD [55].

Further studies of large cohorts of diabetic patients would be necessary to examine the effects of drug dosage and adherence, which may have greater impacts on patients who take insulin than on patients who take oral agents.

In our study, we found no correlation between oral treatment for T2D and cognitive tests.

Our findings therefore provide further evidence that the severity of T2D is associated with a greater compromise of the memory, and that milder forms of T2D may be related with an attention-executive functioning deficit.

The principal strength of the present study is the detailed neuropsychological examination, and the procedure we followed has ensured that the group of selected subjects was characteristically homogeneous from a neuropsychological point of view to ensure a suitable specimen observation.

The main limitations of our study are the small size of our sample and the fact that the data used were cross-sectional, which precludes the determination of causation and monitoring of changes over time. Moreover, different patients of our study refused cerebrospinal fluid evaluation, and also amyloid and fluorodeoxyglucose-PET were performed only in few patients.

Studies with larger numbers of patients should be performed to confirm our preliminary results, and findings regarding insulin use need further support in bigger samples. Future research in following up these subjects in an ongoing longitudinal cognitive aging project may offer further insights into the inter-relationships of T2D, HbA1c, and cardiovascular risk factors with dementia and aging.

\section{Conclusions}

In conclusion, our study suggests an association between T2D and naMCI. In addition, our findings showed that in the T2D-MCI group, patients treated with insulin have worse cognitive performances with a deficit spreading to several cognitive domains, such as memory, attention, executive functions, and visual-spatial abilities.

$\mathrm{MCI}$ early identification and strict monitoring in T2D patients may be relevant to delay the progress of cognitive decline, and the choice of hypoglycemic treatment should be carefully defined.

Author Contributions: Conceptualization, S.V., L.P., R.A.R., and G.P. Data curation, S.V., L.P., S.P., A.R.B., and R.A.R. Formal analysis, M.D.R. Supervision, G.P. Validation, M.D.R. and A.R.B. Writing-original draft, S.V., L.P., S.P., R.A.R., P.P., and G.P. Writing-review \& editing, E.T., P.P., and G.P. All authors have read and agreed to the published version of the manuscript.

Funding: The authors received no financial support for the research, authorship, and/or publication of this article. Acknowledgments: The authors would like to thank Marzio Marcellini for his skillful technical assistance.

Conflicts of Interest: The authors declare no conflict of interest.

\section{Abbreviations}

ADL Activities of Daily Living;

AD Alzheimer's disease;

aMCI amnestic mild cognitive impairment;

aMCI-md amnestic mild cognitive impairment, multi-domain;

aMCI-sd amnestic mild cognitive impairment, single-domain;

FCSRT Free and Cued Selective Reminding Test;

FCSRT ITR Free and Cued Selective Reminding Test, Immediate Total Recall;

FCSRT ISC Free and Cued Selective Reminding Test, Index of Sensitivity of Cueing; 


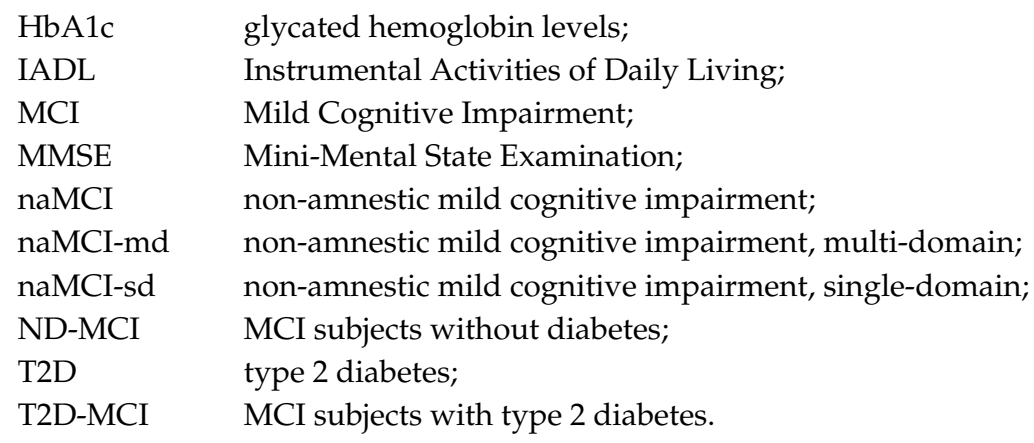

\section{References}

1. Cukierman, T.; Gerstein, H.C.; Williamson, J.D. Cognitive decline and dementia in diabetes-systematic overview of prospective observational studies. Diabetologia 2005, 48, 2460-2469. [CrossRef] [PubMed]

2. Luchsinger, J.A.; Tang, M.X.; Stern, Y.; Shea, S.; Mayeux, R. Diabetes mellitus and risk of Alzheimer's disease and dementia with stroke in a multiethnic cohort. Am. J. Epidemiol. 2001, 154, 635-641. [CrossRef] [PubMed]

3. Ciudin, A.; Espinosa, A.; Simó-Servat, O.; Ruiz, A.; Alegret, M.; Hernández, C.; Boada, M.; Simó, R. Type 2 diabetes is an independent risk factor for dementia conversion in patients with mild cognitive impairment. J. Diabetes Complicat. 2017, 31, 1272-1274. [CrossRef]

4. Li, J.; Cesari, M.; Liu, F.; Dong, B.; Vellas, B. Effects of Diabetes Mellitus on Cognitive Decline in Patients with Alzheimer Disease: A Systematic Review. Can. J. Diabetes 2017, 41, 114-119. [CrossRef] [PubMed]

5. Muñoz-Rivas, N.; Méndez-Bailón, M.; Miguel-Yanes, J.M.; Hernández-Barrera, V.; Miguel-Díez, J.; Jimenez-Garcia, R.; López-de-Andrés, A. Observational study of vascular dementia in the Spanish elderly population according to Type 2 diabetes status: Trends in incidence, characteristics and oucomes (2004-2013). BMJ Open 2017, 7, e016390. [CrossRef]

6. Peila, R.; Rodriguez, B.L.; Launer, L.J. Type 2 diabetes, APOE gene and the risk for dementia and related pathologies: The Honolulu-Asia Aging Study. Diabetes 2002, 51, 1256-1262. [CrossRef]

7. Zhao, W.Q.; De Felice, F.G.; Fernandez, S.; Chen, H.; Lambert, M.P.; Quon, M.J.; Krafft, G.A.; Klein, W.L. Amyloid beta oligomers induce impairment of neuronal insulin receptors. FASEB J. 2008, 22, 246-260. [CrossRef]

8. Arab, L.; Sadeghi, R.; Walker, D.G.; Lue, L.F.; Sabbagh, M.N. Consequences of aberrant insulin regulation in the brain: Can treating diabetes be effective for Alzheimer's disease. Curr. Neuropharmacol. 2011, 9, 693-705. [CrossRef]

9. Roberts, R.O.; Geda, Y.E.; Knopman, D.S.; Christianson, T.J.; Pankratz, V.S.; Boeve, B.F.; Vella, A.; Rocca, W.A.; Petersen, R.C. Association of duration and severity of diabetes mellitus with mild cognitive impairment. Arch. Neurol. 2008, 65, 1066-1073. [CrossRef]

10. Luchsinger, J.A.; Reitz, C.; Patel, B.; Tang, M.X.; Manly, J.J.; Mayeux, R. Relation of diabetes to mild cognitive impairment. Arch. Neurol. 2007, 64, 570-575. [CrossRef]

11. Velayudhan, L.; Poppe, M.; Archer, N.; Proitsi, P.; Brown, R.G.; Lovestone, S. Risk of developing dementia in people with diabetes and mild cognitive impairment. Br. J. Psychiatry 2010, 196, 36-40. [CrossRef]

12. Petersen, R.C. Mild Cognitive Impairment as a diagnostic entity. J. Int. Med. 2004, 256, 183-194. [CrossRef]

13. Yuan, X.I.; Wang, X.G. Mild Cognitive impairment in type 2 diabetes mellitus and related risk factors: A review. Rev. Neurosci. 2017, 28, 715-723. [CrossRef]

14. Gao, Y.; Xiao, Y.; Miao, R.; Zhao, J.; Zhang, W.; Huang, G.; Ma, F. The characteristic of cognitive function in Type 2 diabetes mellitus. Diabetes Res. Clin. Pract. 2015, 109, 299-305. [CrossRef] [PubMed]

15. Ma, F.; Wu, T.; Miao, R.; Xiao, Y.Y.; Zhang, W.; Huang, G. Conversion of mild cognitive impairment to dementia among subjects with diabetes: A population-based study of incidence and risk factors with five years of follow-up. J. Alzheimers Dis. 2015, 43, 1441-1449. [CrossRef] [PubMed]

16. Roberts, R.O.; Knopman, D.S.; Geda, Y.E.; Cha, R.H.; Pankratz, V.S.; Baertlein, L.; Boeve, B.F.; Tangalos, E.G.; Ivnik, J.; Mielke, M.M.; et al. Association of diabetes with amnestic and nonamnestic mild cognitive impairment. Alzheimers Dement. 2014, 10, 18-26. [CrossRef] [PubMed] 
17. Yeung, S.E.; Fischer, A.L.; Dixon, R.A. Exploring Effects of Type 2 Diabetes on Cognitive Functioning in Older Adults. Neuropsychology 2009, 23, 1-9. [CrossRef] [PubMed]

18. Folstein, M.F.; Folstein, S.E.; McHugh, P.R. "Mini-Mental State”. A pratical method for granding the cognitive state of patients for the clinician. J. Psychiatr. Res. 1975, 12, 189-198. [CrossRef]

19. Katz, S.; Ford, A.B.; Moskowitz, R.W.; Jackson, B.A.; Jaffe, M.W. Studies of illness in the aged. The index of ADL: A standardized measure of biological and psychosocial function. JAMA 1963, 185, 914-919. [CrossRef]

20. Lawton, M.P.; Brody, E.M. Assessment of older people: Self-maintaining and instrumental activities of daily living. Gerontologist 1969, 9, 179-186. [CrossRef]

21. American Diabetes Association. Classification and diagnosis of diabetes. Diabetes Care 2018, 41 (Suppl. S1), 513-527.

22. Winblad, B.; Palmer, K.; Kivipelto, M.; Jelic, V.; Fratiglioni, L.; Wahlund, L.O.; Nordberg, A.; Bäckman, L.; Albert, M.; Almkvist, O.; et al. Mild cognitive impairment-beyond controversies, towards a consensus: Report of the International Working Group on Mild Cognitive Impairment. J. Intern Med. 2004, 256, 240-246. [CrossRef] [PubMed]

23. Caffò, A.O.; De Caro, M.F.; Picucci, L.; Notarnicola, A.; Settanni, A.; Livrea, P.; Lancioni, G.E.; Bosco, A. Reorientation deficits are associated with amnestic mild cognitive impairment. Am. J. Alzheimers Dis. Dement. 2012, 27, 321-330. [CrossRef]

24. Spinnler, H.; Tognoni, G. Standardizzazione e Taratura Italiana di Test Neuropsicologici; Masson Italia Periodici: Milan, Italy, 1987; pp. 47-50.

25. Amodio, P.; Wenin, H.; Del Piccolo, F.; Mapelli, D.; Montagnese, S.; Pellegrini, A.; Musto, C.; Gatta, A.; Umiltà, C. Variability of trail making test, symbol digit test and line trait test in normal people. A normative study taking into account age-dependent decline and sociobiological variables. Aging Clin. Exp. Res. 2002, 14, 117-131. [CrossRef] [PubMed]

26. Caffarra, P.; Vezzadini, G.; Dieci, F.; Zonato, F.; Venneri, A. Una versione abbreviata del test di Stroop: Dati normativi nella popolazione italiana. Nuova Riv. Neurol. 2002, 12, 111-115.

27. Laiacona, M.; Inzaghi, M.G.; De Tanti, A.; Capitani, E. Wisconsin card sorting test: A new global score, with Italian norms, and its relationship with the Weigl sorting test. Neurol. Sci. 2000, 21, 279-291. [CrossRef]

28. Gainotti, G.; Marra, C.; Villa, G. A double dissociation between accuracy and time of execution on attentional tasks in Alzheimer's disease and multi-infarct dementia. Brain 2001, 124, 731-738. [CrossRef]

29. Appollonio, I.; Leone, M.; Isella, V.; Piamarta, F.; Consoli, T.; Villa, M.L.; Forapani, E.; Russo, A.; Nichelli, P. The Frontal Assesment Battery (FAB): Normative values in an Italian population sample. Neurol. Sci. 2005, 26, 108-116. [CrossRef]

30. Costa, A.; Bagoj, E.; Monaco, M.; Zabberoni, S.; De Rosa, S.; Papantonio, A.M.; Mundi, C.; Caltagirone, C.; Carlesimo, G.A. Standardization and normative data obtained the Italian population for a new verbal fluency instrument, the phonemic/semantic alternate fluency test. Neurol. Sci. 2014, 35, 365-372. [CrossRef]

31. Monaco, M.; Costa, A.; Caltagirone, C.; Carlesimo, G.A. Forward and backward span for verbal and visuo-spatial data: Standardization and normative data from an Italian adult population. Neurol. Sci. 2013, 34, 749-754. [CrossRef]

32. Carlesimo, G.A.; Caltagirone, C.; Gainotti, G. The Mental Deterioration Battery: Normative data, diagnostic reliability and qualitative analyses of cognitive impairment. The Group for the Standardization of the Mental Deterioration Battery. Eur. Neurol. 1996, 36, 378-384. [CrossRef]

33. Novelli, G.; Papagno, C.; Capitani, E.; Laiacona, M. Tre test clinici di memoria verbale a lungo termine. Taratura su soggetti normali. Arch. Psicol. Neurol. Psichiatr. 1986, 47, 278-296.

34. Frasson, P.; Ghiretti, R.; Catricalà, E.; Pomati, S.; Marcone, A.; Parisi, L.; Rossini, P.M.; Cappa, S.F.; Mariani, C.; Vanacore, N.; et al. Free and Cued Selective Reminding Test: An Italian normative study. Neurol. Sci. 2011, 32, 1057-1062. [CrossRef] [PubMed]

35. Luzzi, S.; Pesallaccia, M.; Fabi, K.; Muti, M.; Viticchi, G.; Provinciali, L.; Piccirilli, M. Non-verbal memory measured by Rey-Osterrieth Complex Figure B: Normative data. Neurol. Sci. 2011, 32, 1081-1089. [CrossRef] [PubMed]

36. Capasso, R.; Miceli, G. Esame Neuropsicologico per l'Afasia, 1st ed.; Springer: Milan, Italy, 2001.

37. Catricalà, E.; Della Rosa, P.A.; Ginex, V.; Mussetti, Z.; Plebani, V.; Cappa, S.F. An Italian battery for the assessment of semantic memory disorders. Neurol. Sci. 2013, 34, 985-993. [CrossRef] 
38. Zhang, X.; Jiang, X.; Han, S.; Liu, Q.; Zhou, J. Type 2 Diabetes Mellitus Is Associated with the Risk of Cognitive Impairment: A Meta-Analysis. J. Mol. Neurosci. 2019, 68, 251-260. [CrossRef]

39. Bruce, D.G.; Davis, W.A.; Casey, G.P.; Starkstein, S.E.; Clarnette, R.M.; Almeida, O.P.; Davis, T.M. Predictors of cognitive decline in older individuals with diabetes. Diabetes Care 2008, 31, 2103-2107. [CrossRef]

40. Winkler, A.; Dlugaj, M.; Weimar, C.; Jöckel, K.H.; Erbel, R.; Dragano, N.; Moebus, S. Association of diabetes mellitus and mild cognitive impairment in middle-aged men and women. J. Alzheimers Dis. 2014, 42, 1269-1277. [CrossRef]

41. Schmidtke, K.; Hermeneit, S. High rate of conversion to Alzheimer's disease in a cohort of amnestic MCI patients. Int. Psychogeriatr. 2008, 20, 96-108. [CrossRef]

42. Reinvang, I.; Grambaite, R.; Espeseth, T. Executive Dysfunction in MCI: Subtype or Early Symptom. Int. J. Alzheimer's Dis. 2012, 2012, 936272. [CrossRef]

43. Dubois, B.; Feldman, H.H.; Jacova, C.; Dekosky, S.T.; Barberger-Gateau, P.; Cummings, J.; Delacourte, A.; Galasko, D.; Gauthier, S.; Jicha, G.; et al. Research criteria for the diagnosis of Alzheimer's disease: Revising the NINCDS-ADRDA criteria. Lancet Neurol. 2007, 6, 734-746. [CrossRef]

44. Chasles, M.J.; Tremblay, A.; Escudier, F.; Lajeunesse, A.; Benoit, S.; Langlois, R.; Joubert, S.; Rouleau, I. An examination of semantic impairment in Amnestic MCI and AD: What can we learn from verbal fluency? Arch. Clin. Neuropsychol. 2019, 35, 22-30. [CrossRef] [PubMed]

45. Sano, M.; Zhu, C.W.; Grossman, H.; Schimming, C. Longitudinal Cognitive Profiles in Diabetes: Results From the National Alzheimer's Coordinating Center's Uniform Data. J. Am. Geriatr. Soc. 2017, 65, 2198-2204. [CrossRef] [PubMed]

46. Ganguli, M.; Jia, Y.; Hughes, T.F.; Snitz, B.E.; Chang, C.H.; Berman, S.B.; Sullivan, K.J.; Kamboh, M.I. Mild Cognitive Impairment That Does Not Progress To Dementia: A Population-Based Study. J. Am. Geriatr. Soc. 2019, 67, 232-238. [CrossRef]

47. Dos Santos Matioli1, M.N.P.; Suemoto, C.K.; Rodriguez, R.D.; Farias, D.S.; da Silva, M.M.; Leite, R.E.P.; Ferretti-Rebustini, R.E.L.; Pasqualucci, C.A.; Filho, W.J.; Grinberg, L.T.; et al. Association between diabetes and causes of dementia: Evidence from a clinicopathological study. Dement Neuropsychol. 2017, 11, 406-412. [CrossRef]

48. Klein, J.P.; Waxman, S.G. The brain in diabetes: Molecular changes in neurons and their implications for end-organ damage. Lancet Neurol. 2003, 2, 548-554. [CrossRef]

49. Ott, A.; Stolk, R.P.; van Harskamp, F.; Pols, H.A.; Hofman, A.; Breteler, M.M. Diabetes mellitus and the risk of dementia: The Rotterdam Study. Neurology 1999, 53, 1937-1942. [CrossRef]

50. De la Monte, S.M.; Wands, J.R. Alzheimer's disease is type 3 diabetes-Evidence reviewed. J. Diabetes Sci. Technol. 2008, 2, 1101-1113. [CrossRef]

51. Devaskar, S.U.; Giddings, S.J.; Rajakumar, P.A.; Carnaghi, L.R.; Menon, R.K.; Zahm, D.S. Insulin gene expression and insulin synthesis in mammalian neuronal cells. J. Biol. Chem. 1994, 269, 8445-8454.

52. Craft, S.; Watson, G.S. Insulin and neurodegenerative disease: Shared and specific mechanisms. Lancet Neurol. 2004, 3, 169-178. [CrossRef]

53. De Santi, S.; de Leon, M.J.; Rusinek, H.; Convit, A.; Tarshish, C.Y.; Roche, A.; Tsui, W.H.; Kandil, E.; Boppana, M.; Daisley, K.; et al. Hippocampal formation glucose metabolism and volume losses in MCI and AD. Neurobiol. Aging 2001, 22, 529-539. [CrossRef]

54. Ferreira, L.S.S.; Fernandes, C.S.; Vieira, M.N.N.; De Felice, F.G. Insulin Resistance in Alzheimer's Disease. Front. Neurosci. 2018, 12, 830. [CrossRef] [PubMed]

55. Biessels, G.J.; Despa, F. Cognitive decline and dementia in diabetes mellitus: Mechanisms and clinical implications. Nat. Rev. Endocrinol. 2018, 14, 591-604. [CrossRef] [PubMed]

(C) 2020 by the authors. Licensee MDPI, Basel, Switzerland. This article is an open access article distributed under the terms and conditions of the Creative Commons Attribution (CC BY) license (http://creativecommons.org/licenses/by/4.0/). 